\title{
Metabolic Control Analysis in a Cellular Model of Elevated MAO-B: Relevance to Parkinson's Disease
}

\author{
Jyothi K. Mallajosyula $\cdot$ Shankar J. Chinta $\cdot$ \\ Subramanian Rajagopalan · David G. Nicholls • \\ Julie K. Andersen
}

Received: 10 December 2008/Revised: 6 January 2009/Accepted: 6 February 2009/Published online: 5 March 2009

(C) The Author(s) 2009. This article is published with open access at Springerlink.com

\begin{abstract}
We previously demonstrated that spare respiratory capacity of the TCA cycle enzyme alpha-ketoglutarate dehydrogenase (KGDH) was completely abolished upon increasing levels of MAO-B activity in a dopaminergic cell model system (Kumar et al., J Biol Chem 278:46432-46439, 2003). MAO-B mediated increases in $\mathrm{H}_{2} \mathrm{O}_{2}$ also appeared to result in direct oxidative inhibition of both mitochondrial complex I and aconitase. In order to elucidate the contribution that each of these components exerts over metabolic respiratory control as well as the impact of MAO-B elevation on their spare respiratory capacities, we performed metabolic respiratory control analysis. In addition to $\mathrm{KGDH}$, we assessed the activities and substrate-mediated respiration of complex I, pyruvate dehydrogenase (PDH), succinate dehydrogenase (SDH), and mitochondrial aconitase in the absence and presence of complex-specific inhibitors in specific and mixed substrate conditions in mitochondria from our MAO-B elevated cells versus controls. Data from this study indicates that Complex I and $\mathrm{KGDH}$ are the most sensitive to inhibition by MAO-B mediated $\mathrm{H}_{2} \mathrm{O}_{2}$ generation, and could be instrumental in determining the fate of mitochondrial metabolism in this cellular PD model system.
\end{abstract}

Keywords Mitochondrial dysfunction - Monoamine oxidase B · Hydrogen peroxide - Krebs cycle enzymes . Metabolic control analysis - Reactive oxygen species

J. K. Mallajosyula $\cdot$ S. J. Chinta $\cdot$ S. Rajagopalan

D. G. Nicholls · J. K. Andersen ( $\square)$

Buck Institute for Age Research, Novato, CA 94945, USA

e-mail: jandersen@buckinstitute.org

\section{Introduction}

Mitochondrial dysfunction due to impaired oxidative phosphorylation has been implicated as a major factor in the pathogenesis of several neurodegenerative disorders. It has, for example, been associated with defects in various mitochondrial respiratory chain or related complexes in Parkinson's disease (PD), Alzheimer's disease (AD), Huntington's disease (HD), and Friedreich's ataxia (Schapira 1999). Reductions in activities of both mitochondrial complex I(CI) (Schapira et al. 1989, 1990) and the TCA cycle enzyme alpha-ketoglutarate dehydrogenase (KGDH) (Mizuno et al. 1994) which provides substrate for the complex are in fact physiological hallmarks associated with human PD neuropathology.

Elevations in the catecholamine-oxidizing enzyme monoamine oxidase-B (MAO-B) have been suggested to contribute to PD neuropathology (Cohen and Kesler 1999). Substrate oxidation by the enzyme is accompanied stoichiometrically by the reduction of oxygen to $\mathrm{H}_{2} \mathrm{O}_{2}$ which in turn can lead to cellular damage (Vindis et al. 2001; Cohen et al. 1997). We previously demonstrated that subtle increases in MAO-B levels mimicking those which occur with age in a genetically engineered dopaminergic PC12 cell line resulted in increased $\mathrm{H}_{2} \mathrm{O}_{2}$ production and selective decreases in the activities of both $\mathrm{CI}$ and $\mathrm{KGDH}$ (Kumar et al. 2003). MAO-B elevation was found to abolish the spare KGDH threshold capacity that normally requires significant inhibition before affecting maximal mitochondrial oxygen consumption rates. This in turn was found to compromise the ability of dopaminergic neurons to cope with increased energetic stress.

Various additional metabolic pathway components may also be impacted by oxidative stress as a consequence of MAO-B increase resulting in a cumulative disruptive effect 
on general mitochondrial respiratory function. The activity of any single component enzyme must be inhibited, however, to a particular threshold level before it affects metabolism as a whole (i.e., each enzyme has a 'reserve capacity') (Rossignol et al. 2003). Stress conditions (such as increased oxidative stress) can change the reserve capacities of mitochondrial enzymes and, by doing so, may compromise the cell's ability to maintain metabolic function. Here we attempt to more fully characterize the impact of MAO-B elevation on mitochondrial bioenergetics. We investigated the respiratory thresholds of several possible contributors to NADH levels as a substrate for cellular respiration including the mitochondrial electron transfer chain enzymes CI and CII (SDH) and the TCA cycle enzymes aconitase, $\mathrm{KGDH}$, and pyruvate dehydrogenase (PDH). We measured both basal respiratory thresholds and losses in spare capacities of these enzymes in the oxidative stress condition derived from $\mathrm{H}_{2} \mathrm{O}_{2}$ generation as a consequence of MAO-B elevation in our model system.

\section{Materials and Methods}

All chemicals were obtained from Sigma unless and otherwise noted.

\section{Doxycycline (dox)-Inducible MAO-B Expressing PC12 Cell Lines}

Cell lines expressing MAO-B under transcriptional regulation by doxycycline (dox) (Kumar et al. 2003) were maintained in DMEM containing 10\% FBS, 5\% horse serum, and $1 \%$ streptomycin-penicillin in the presence of $200 \mu \mathrm{g} / \mathrm{ml}$ of G418; the cells were neuronally differentiated via exposure to $50 \mathrm{ng} / \mathrm{ml}$ nerve growth factor (NGF) for a 2 day period before addition of dox to induce MAO-B elevations.

\section{Mitochondrial Preparation}

Mitochondria were prepared by homogenizing cells in mitochondrial medium containing $320 \mathrm{mM}$ sucrose, $5 \mathrm{mM}$ TES, and $1 \mathrm{mM}$ EGTA, centrifuging the homogenate at $1000 \times g$, and pelleting the mitochondria in the resulting supernatant at $10000 \times g$. The mitochondria were resuspended in $250 \mathrm{mM}$ sucrose, $10 \mathrm{mM}$ TES, and $0.1 \%(\mathrm{w} / \mathrm{v})$ fatty acid free BSA, pH 7.2 for complex I, KGDH, and citrate synthase assays.

\section{Complex I Activity}

Activity was assayed in homogenates from isolated mitochondria as rotenone-sensitive $\mathrm{NADH}$ dehydrogenase activity by measuring 2,6-dichlorophenolindophenol (DCIP) reduction in mitochondrial extract following addition of $200 \mu \mathrm{M}$ NADH, $200 \mu \mathrm{M}$ decylubiquinone, $2 \mathrm{mM}$ $\mathrm{KCN}$, and $0.002 \%$ DCIP in the presence and absence of $2 \mu \mathrm{M}$ rotenone (Trounce et al. 1996). Values for this and all subsequent assays were normalized per protein using BioRad reagent.

\section{KGDH Activity}

KGDH activity was assayed as the rate of $\mathrm{NAD}^{+}$ reduction at $340 \mathrm{~nm}$ upon addition of $5.0 \mathrm{mM} \mathrm{MgCl}$, $40.0 \mu \mathrm{M}$ rotenone, $2.5 \mathrm{mM} \alpha$-ketoglutarate, $0.1 \mathrm{mM}$ CoA, $0.2 \mathrm{mM}$ thymine pyrophosphate, and $1.0 \mathrm{mM}$ NAD to freeze-thawed mitochondria (Nulton-Persson and Szweda 2001). Citrate synthase activity, used to normalize the mitochondrial load, was measured by assessing the change in $\mathrm{A}_{412}$ reduction of $2.0 \mathrm{mM}$ DTNB in presence of $6 \mathrm{mM}$ acetyl CoA and $10 \mathrm{mM}$ oxaloacetate (Trounce et al. 1996).

\section{Aconitase Activity}

Aconitase activity was assayed as the rate of $\mathrm{NADP}^{+}$ reduction at $340 \mathrm{~nm}$ upon addition of $30 \mathrm{mM}$ sodium citrate, $0.6 \mathrm{mM}$ fresh $\mathrm{MnCl}_{2}, 0.2 \mathrm{mM} \mathrm{NADP}$, and $2 \mathrm{U} / \mathrm{ml}$

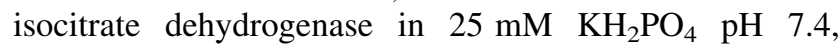
$0.5 \mathrm{mM}$ EDTA to the mitochondrial preparation.

\section{SDH Activity}

Succinate dehydrogenase activity was assayed as DCIP reduction at $600 \mathrm{~nm}$ upon addition of $20 \mathrm{mM}$ succinate, $2 \mathrm{mM} \mathrm{KCN}, 200 \mu \mathrm{M}$ decylubiquinone, and $0.002 \%$ DCIP in $25 \mathrm{mM} \mathrm{KH}_{2} \mathrm{PO}_{4} \mathrm{pH} 7.4,0.5 \mathrm{mM}$ EDTA to the mitochondria preparation after activation for $15 \mathrm{~min}$ at $30^{\circ} \mathrm{C}$ to compete out oxaloacetic acid (OAA) in the presence of succinate and $\mathrm{KCN}$.

\section{PDH Activity}

Pyruvate dehydrogenase was assayed as the reduction of DTNB at $412 \mathrm{~nm}$ by first incubating the mitochondrial preparation in the solution containing $2 \mathrm{mM}$ TPP, $10 \mathrm{mM}$ DTT and $10 \mathrm{mM}$ sodium pyruvate, $1 \mathrm{mM} \mathrm{MgCl}_{2}$, and $2 \mathrm{mM} \mathrm{NAD}^{+}$, with or without $0.2 \mathrm{mM}$ sodium Co-A for $15 \mathrm{~min}$ at $30^{\circ} \mathrm{C}$ followed by addition of $25 \mathrm{mM} \mathrm{OAA}$ and $0.05 \% \mathrm{DTNB}$, equilibrating for $10 \mathrm{~min}$, and addition of $5 \mathrm{U} / \mathrm{ml}$ citrate synthase. The difference change in absorbance over time at $412 \mathrm{~nm}$ was recorded in the absence or presence of sodium Co-A. 


\section{Oxygen Consumption}

Substrate-specific respiration was assayed in fresh mitochondrial preparations from dox-induced and uninduced cells in a buffer containing $125 \mathrm{mM} \mathrm{KCl,} 2 \mathrm{mM} \mathrm{KH}{ }_{2} \mathrm{PO}_{4}$, $1 \mathrm{mM} \mathrm{MgCl}_{2}$, and $20 \mathrm{mM}$ HEPES pH 7.0 (Murphy et al. 1996) at $30^{\circ} \mathrm{C}$ using a Clarke electrode (Hansatech). Respiration was calculated as the rate of oxygen consumption using either $5.0 \mathrm{mM}$ pyruvate $/ 5.0 \mathrm{mM}$ malate as substrates for $\mathrm{PDH}, 5.0 \mathrm{mM}$ citrate $/ 5.0 \mathrm{mM}$ malate as substrates for aconitase, $5.0 \mathrm{mM}$ glutamate $/ 5.0 \mathrm{mM}$ malate as substrates for complex I, or $5.0 \mathrm{mM} \alpha$-ketoglutarate $/ 5.0 \mathrm{mM}$ malate as substrates for $\mathrm{KGDH}$ in presence or absence of selective inhibition with $0-100 \mathrm{nM}$ arsenite (KGDH) or $2.0 \mu \mathrm{M}$ rotenone (complex I), respectively. FCCP $(10 \mu \mathrm{M})$ was added as uncoupler to assess maximum respiration rates.

\section{Inhibitor Titrations}

Inhibitor titrations were performed to assess threshold values and control coefficients. Specific enzyme inhibitors used for titration included arsenite/bromopyruvate for $\mathrm{PDH}$, arsenite alone for KGDH, fluorocitrate for aconitase, malonate for SDH, and rotenone for complex I-mediated respiration analyses. To allow maximal contribution of every component enzyme, respiration was also carried out using a mixed cocktail of substrates containing $5 \mathrm{mM}$ each of pyruvate, malate, citrate, $\alpha$-ketoglutarate, and glutamate in the presence of specific separate inhibitors to titrate out individual enzymes. Since arsenite is not specific for $\mathrm{KGDH}$, respiration mediated by $\mathrm{KGDH}$ alone was also assayed in the presence of $20 \mathrm{mM}$ bromopyruvate to inhibit PDH and its effects. The inhibitor concentrations used were determined by using close approximations of the published $K$. Relative dissociation constants pertinent for each enzyme were calculated using a derivation of the Michaelis-Menten equation, $K_{\mathrm{d}}=[I] /\left(\left(V_{\mathrm{o}} / V_{\mathrm{i}}\right)-1\right)$, where $V_{\mathrm{i}}$ is the inhibited rate of enzyme, $V_{\mathrm{o}}$ is the initial rate and $[I]$ is the inhibitor concentration. For our purposes, a $V_{\mathrm{o}}$ was set at a relative $100 \%$ and $V_{\mathrm{i}}$ at a point close but not equal to zero where the enzyme activity is minimal. Control coefficients quantitatively describe the control exerted by each enzyme in a metabolic network over substrate flux (Cascante et al. 2002). We calculated the control coefficients $\left(C_{\mathrm{i}}\right)$ of respiration of the component enzymes using the equation (Davey et al. 1998):

$C_{\mathrm{i}}=(\mathrm{d} J / J) /\left(\mathrm{d}[I] / K_{\mathrm{d}}\right)$

where $C_{\mathrm{i}}$ is the control coefficient, $\mathrm{d} J$ is the decrement in flux, $J$ is the total flux of the substrate, $\mathrm{d} I$ is the decrement in inhibitor concentration, and $K_{\mathrm{d}}$ is the dissociation constant. To simplify this calculation, we used $(\mathrm{d} J / \mathrm{d} I)$, the initial slope of the titration curve, and $\mathrm{J}$, the uninhibited respiration rate, at $100 \%$ in our relative system (Kunz et al. 1999):

$C_{\mathrm{i}}=(\mathrm{d} J / \mathrm{d} I)\left(K_{\mathrm{d}} / J\right)$

Statistical analysis

Data is expressed as mean $\pm \mathrm{SD}$ and significance testing was performed using ANOVA.

\section{Results}

MAO-B Mediated $\mathrm{H}_{2} \mathrm{O}_{2}$ Generation Inhibits Mitochondrial Enzymes

To study the effects of $\mathrm{H}_{2} \mathrm{O}_{2}$ generated by inducible increases in MAO-B levels on individual respiratory components in our dopaminergic cell system (Kumar et al. 2003), we measured enzyme activities in mitochondrial preparations from uninduced versus dox-induced cells expressing MAO-B in either the absence or presence of the MAO-B inhibitor deprenyl. MAO-B elevation was found to substantially inhibit mitochondrial aconitase, $\mathrm{KGDH}$, complex I, succinate dehydrogenase, and PDH activities to an extent ranging from $33.5 \%$ to nearly $60 \%$; these inhibitions were deprenyl-sensitive (Fig. 1) and prevented by catalase pretreatment (Kumar et al. 2003) (data not shown for aconitase, $\mathrm{SDH}$ and $\mathrm{PDH}$ ) suggesting that they were both MAO-B and $\mathrm{H}_{2} \mathrm{O}_{2}$-dependent.

\section{Respiratory Thresholds and Spare Capacities}

Specific inhibitor titrations were initially performed in order to identify the appropriate inhibitor range to be used for each enzyme. This inhibitor range was subsequently used to perform measurements of substrate-specific respiration. Enzyme inhibition versus respiration was plotted for each enzyme in order to determine respiratory thresholds and spare capacities for each in the absence and presence of MAO-B induction (Fig. 2, Table 1).

Aconitase was found to have a spare capacity of $189 \%$ that is reduced to $89 \%$ following MAO-B induction as indicated by the intercept of the slope at the point of total respiratory inhibition (Fig. 2a). The threshold value was determined to be reduced by $19 \%$ in MAO-B-expressing versus control conditions (66\% vs. $47 \%$, Table 1 ).

Complex I was found to have a very low spare capacity (7\%) that was reduced to zero by MAO-B increase (Fig. 2b). The threshold value of $7.2 \%$ in uninduced cells was reduced to a negative value of $3.37 \%$ following MAO$\mathrm{B}$ induction, a total shift of 10.54 (Table 1). This alteration was mirrored when respiration was measured using a substrate mix instead of glutamate/malate alone. 
Fig. 1 Mitochondrial enzyme activities are inhibited via MAO-B elevation. Activities of the major mitochondrial enzymes involved in NADH/ FADH production were measured in mitochondrial preparations from uninduced (left bars), dox-induced (middle bars) and dox-deprenyl cotreated cells (right bars). $n=5$ per condition from three separate experiments, values are expressed as mean $\pm \mathrm{SD}$,

$* P<0.01$ compared to no dox

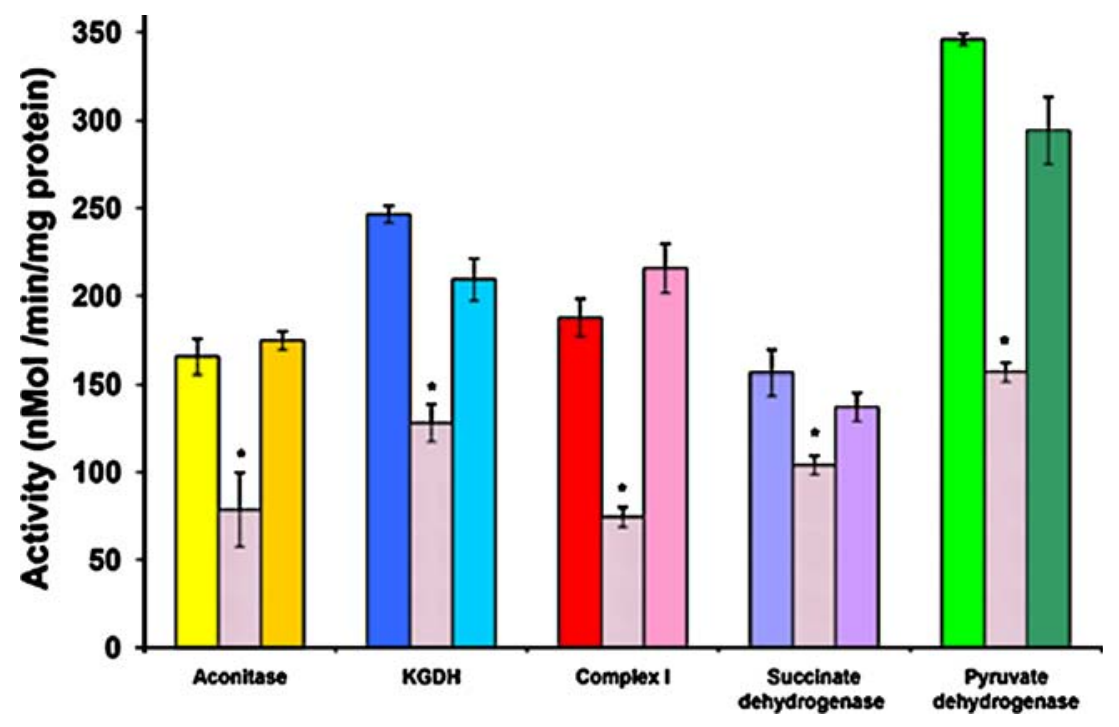

SDH and PDH, though vastly different enzyme complexes, behaved in a similar fashion in this study. Mitochondria have a very high capacity to consume oxygen using specific substrates for these enzyme complexes; both enzymes require significant inhibition before respiratory capacity is diminished (Fig. 2). Though both these enzymes have sensitivity to hydrogen peroxide as reflected by the MAO-B induced reduction in their specific activities (Fig. 1), they appear to have a very high uninduced spare capacity, $250 \%$ and $415 \%$, respectively (Table 1, Fig. 2c, d). MAO-B elevation reduces this spare capacity only slightly, from $250 \%$ to $196 \%$ in the case of SDH and $415 \%$ to $348 \%$ in the case of PHD. Threshold values were determined to be $74 \%$ and $82 \%$ inhibition, respectively, which transitioned only slightly following MAO-B increase $(68 \%$ and $77 \%$, respectively, Table 1$)$.

For KDGH, we observed a decrease from $57 \%$ spare capacity to 5\% under conditions of MAO-B elevation and the threshold value for inhibition by arsenite was shifted from $36 \%$ to $4.6 \%$ under this stress condition (Fig. 2e, Table 1). Since KGDH is structurally and catalytically similar to pyruvate PDH and therefore conditions that inhibit the former may inhibit PDH as well, we also assessed KDGH inhibition and titration of arsenite-sensitive KGDH dependent respiration in the presence of the specific PDH inhibitor, bromopyruvate. In order to mimic cellular conditions where substrate levels are not limiting, we used a substrate mixture that included all those specific for the enzymes being examined in our studies. Succinate addition was avoided since SDH displayed an overwhelming control over respiration masking the contribution from other components (data not shown). Similar assessment of effects of titration using other inhibitors in the presence of a mixed substrate cocktail without succinate yielded similar results (data not shown).
We found that under conditions in which PDH is inhibited by bromopyruvate, KDGH had a higher threshold value (62.8\%) which dropped to zero in the presence of MAO-B increase (Fig. 2f). The threshold of inhibition by arsenite was found to shift from $38.8 \%$ to less than zero in the presence of up-regulation of MAO-B (Table 1).

\section{Control Coefficients}

Flux control analysis (Kacser and Burns 1973, 1979) represents an approach that can provide important insights into the functional role of the respiratory chain in various conditions. If a metabolic pathway is composed of distinct enzymes, the extent to which each enzyme is rate-controlling may be different and the sum of all the flux control coefficients for the different enzymes should be equal to unity (Kacser and Burns 1979; Brand et al. 1994). In our experiments, the enzymes examined are various contributors to the final end-product, i.e., NADH, which is then oxidized as substrate by CI thus initiating the mitochondrial oxidative phosphorylation cycle. SDH contributes to this at two levels-first during the TCA cycle and later during ubiquinone reduction. The reactions measured therefore could be part of a branched pathway and hence the flux control coefficients could total greater than one (Cornish-Bowden 2004). In order to acquire an elementary understanding of relative contributions of the participant enzymes on total NADH generation in particular and on oxidative phosphorylation in general, we measured the relative change in control coefficients between the two conditions, i.e., the uninduced control and in the presence of MAO-B mediated $\mathrm{H}_{2} \mathrm{O}_{2}$ generation (Table 2). Increased levels of MAO-B resulted in a shift in the metabolic control of respiration. Interestingly, CI was found to exert maximal respiratory control in both basal conditions (flux 

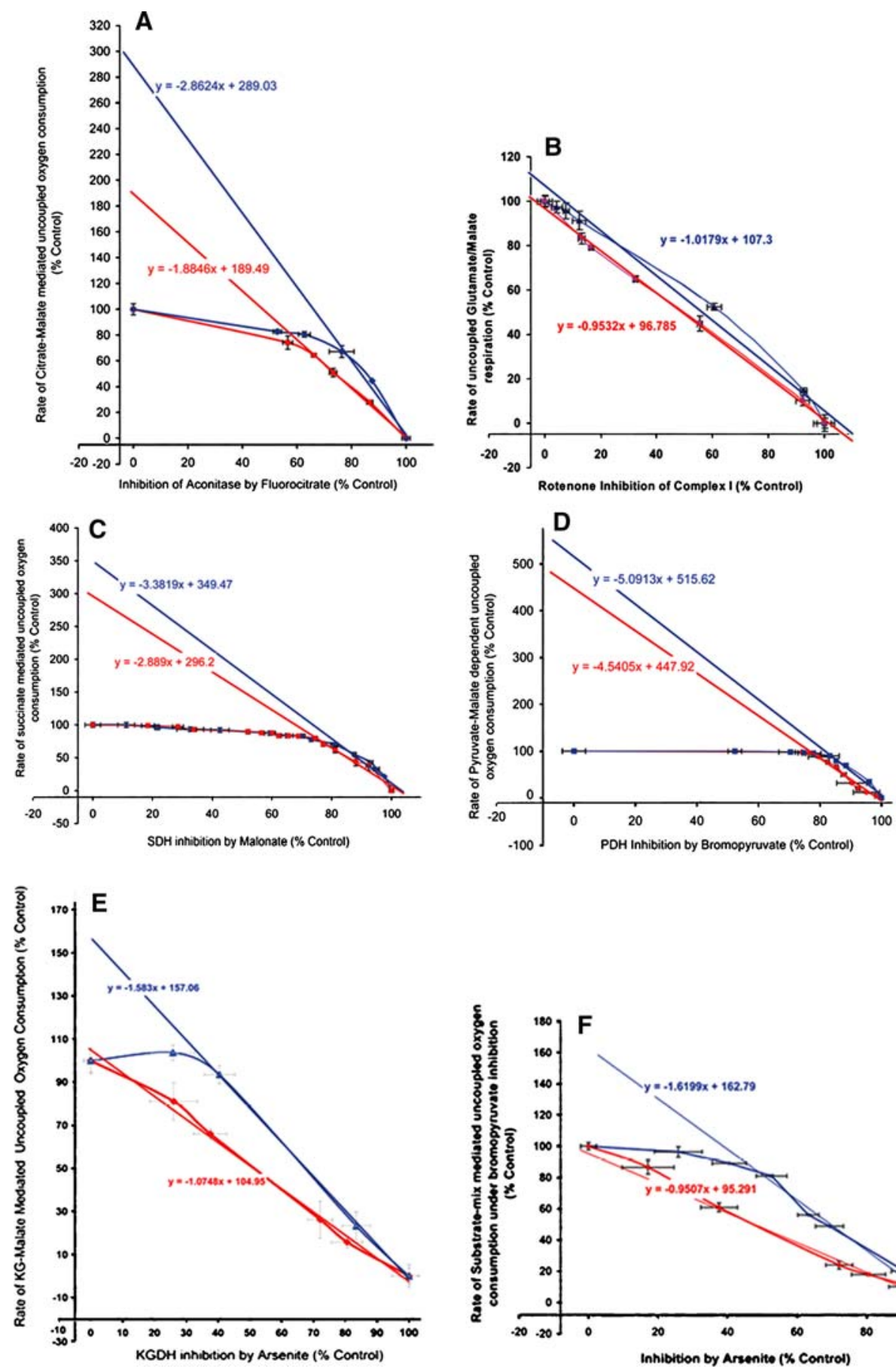

Fig. 2 Alterations in respiratory threshold values of NADH-dependent enzymes under conditions of MAO-B-induced stress. Inhibitor titrations of uncoupled substrate dependent respiration were plotted against relative inhibition of activity by enzyme-specific specific inhibitors in mitochondria isolated from uninduced control cells (blue) versus dox-induced cells expressing elevated MAO-B levels (red). The curves, plotted as trends of the data points shown are: fluorocitrate inhibition of mitochondrial aconitase (a), rotenone inhibition of CI (b), malonate inhibition of SDH (c), bromopyruvate (BrPy) inhibition of PDH (d), arsenite inhibition of $\mathrm{KGDH}(\mathbf{e})$, and arsenite inhibition of KGDH in a background of a total inhibition of $\mathrm{PDH}$ by $\mathrm{BrPy}(\mathbf{f})$. Threshold values are calculated as the abscissa at

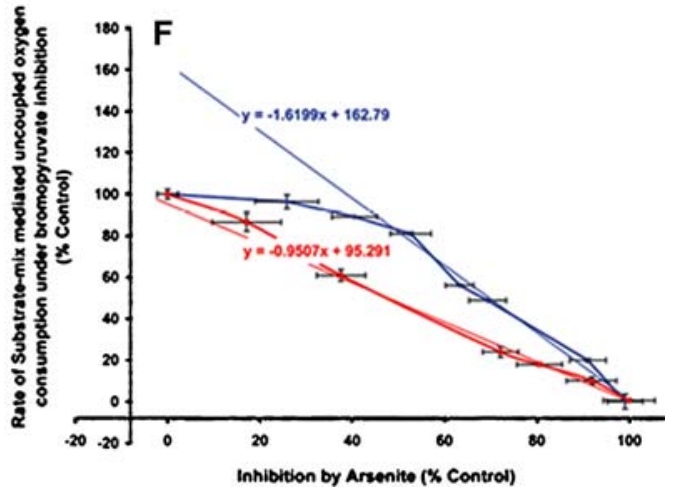

$0 \%$ inhibition on the trends drawn at maximal inhibition. The straight equations represent the respective uninduced (blue) and induced (red) trends drawn at near total inhibition of uncoupled respiration and activity by the enzyme-specific inhibitor. Respiratory spare capacity is derived by the difference between maximum respiration $(100 \%)$ and the ' $y$ ' intercept of the trend line (at zero inhibition). Dotted trends and equations at initial points in the curve are used for calculation of the control coefficients. Actual maximal and minimal respiration and activity is adjusted to 100 and 0 percent values to enable comparison and residual inhibitor independent respiration by the mitochondria has been discounted to facilitate comparative analysis 
Table 1 Spare capacities and threshold values

\begin{tabular}{|c|c|c|c|c|c|}
\hline \multirow[t]{2}{*}{ Enzyme } & \multicolumn{2}{|c|}{$\%$ Spare capacity } & \multicolumn{3}{|c|}{$\%$ Threshold value of inhibition } \\
\hline & Uninduced & Induced & Uninduced & Induced & Reduction \\
\hline Aconitase & 189.03 & 89.49 & 66.02 & 47.48 & 18.54 \\
\hline$\alpha \mathrm{KGDH}$ & 57.06 & 4.95 & 36.05 & 4.60 & 31.45 \\
\hline$\alpha \mathrm{KGDH}$ with (BrPy) & 62.79 & $<0$ & 38.76 & -4.95 & 43.71 \\
\hline Complex I & 7.30 & $<0$ & 7.17 & -3.37 & 10.54 \\
\hline $\mathrm{SDH}$ & 249.47 & 196.20 & 73.83 & 67.91 & 5.92 \\
\hline PDH & 415.62 & 347.92 & 81.63 & 76.63 & 5.00 \\
\hline
\end{tabular}

Respiratory spare capacity and the threshold value of inhibition of respiration derived from inhibitor titration of each the mitochondrial enzymes examined. Spare capacity represents maximal uncoupled oxygen consumption during complete enzyme inhibition. Threshold values reflect total inhibition of activity necessary before respiration is affected and the reduction of the threshold value represents the shift resulting from MAO-B induction. The values are represented as \% changes from uninhibited maximal uncoupled oxygen consumption

Table 2 Respiratory flux control coefficients

\begin{tabular}{|c|c|c|c|c|c|}
\hline \multirow[t]{2}{*}{ Enzyme } & \multirow[t]{2}{*}{$K_{\mathrm{d}}$ (inhibitor) } & & \multicolumn{3}{|l|}{$C_{\mathrm{i}}$} \\
\hline & & & Uninduced & Induced & Fold change \\
\hline Aconitase & Fluorocitrate & $2.88 \mu \mathrm{M}$ & 0.0086 & 0.0180 & 2.10 \\
\hline$\alpha \mathrm{KGDH}$ & Arsenite & $2.97 \mathrm{nM}$ & 0.0691 & 0.1120 & 1.62 \\
\hline$\alpha \mathrm{KGDH}$ with (BrPy) & Arsenite & $2.97 \mathrm{nM}$ & 0.0777 & 0.7560 & 9.73 \\
\hline Complex I & Rotenone & $43.19 \mathrm{nM}$ & 0.3611 & 0.6457 & 1.79 \\
\hline $\mathrm{SDH}$ & Malonate & $34.33 \mu \mathrm{M}$ & 0.0763 & 0.0644 & 0.84 \\
\hline PDH & Bromopyruvate & $2.63 \mu \mathrm{M}$ & 0.0315 & 0.0295 & 0.94 \\
\hline
\end{tabular}

$K_{\mathrm{d}}(\operatorname{app})=[I] /\left(\left(V_{\mathrm{o}}-V_{\mathrm{i}}\right)-1\right) ; C_{\mathrm{i}}=(\mathrm{d} J / J) /\left(\mathrm{d} I / K_{\mathrm{d}}\right)$

Respiratory flux control by the individual mitochondrial enzymes examined in this study. The flux control coefficient of respiration $\left(C_{\mathrm{i}}\right)$ is derived as a function of the change in inhibition of enzyme activity and the corresponding change in respiration at that inhibition at the initial stages of inhibition where $\mathrm{d} J / J$ represents rate of change in respiration and $\mathrm{d} I / K_{\mathrm{d}}$ represents the rate of change in inhibition. $K_{\mathrm{d}}$ is the apparent inhibitor dissociation constant. These values are derived from the inhibitor titration curves of individual enzyme activities and initial points in the substrate-specific respiration, as in Fig. 2 respectively

coefficient, 0.36 and following MAO-B induction (doubled to 0.65$)$.

\section{Discussion}

Investigation of mitochondrial oxidative phosphorylation using metabolic control analysis (MCA) allows examination of the contribution of various metabolic activities on disease states involving mitochondrial dysfunction. Measurement of the impact of increasing concentrations of specific inhibitors on enzyme activities versus substrate-specific respiration is used to obtain titration curves for graphical determination of flux control coefficients, an index of each component enzyme's contribution to mitochondrial function (Cascante et al. 2002). Determination of the control coefficients within a given pathway determines which portion of the pathway is rate-limiting and can indicate the most efficient point of intervention. This utility can be exploited to identify key targets in disease pathways leading to drug discovery. As an example, moderate effects on the activities of respiratory chain components upstream and including cytochrome oxidase (COX) by either inhibitors, mutations or physiological changes can result in dramatic changes in COX threshold and respiratory control by the enzyme, thereby affecting a disease phenotype (Villani and Attardi 1997). Though MCA is probably too simple to account for the complexity of all disease-related enzymes, it has revealed the existence of thresholds in terms of enzymatic defects in oxidative phosphorylation associated with known mitochondrial disease mutations that impact on fluxes associated with enzymatic reserve (Mazat et al. 2001). Disease manifestation was found in these cases to only appear when the activity of a metabolic step had been reduced to a low level. Threshold effects have been used for the functional determination of different mitochondrial defects, often by measuring maximal rates of respiration and the effect of specific inhibitors (Davey et al. 1997, 1998; Letellier et al. 1994; Villani et al. 1998; Davey and Clark 1996). The significance of alterations in the activities of individual 
mitochondrial bioenergetic components cannot be fully assessed in terms of mitochondrial function without an assessment of the relative control strengths of each component (Harper et al. 1998).

In this study, we attempted to perform a limited MCA of various enzymes affecting respiratory rates especially under a condition of increased oxidative stress as a consequence of MAO-B elevation. Generation of $\mathrm{H}_{2} \mathrm{O}_{2}$ via increased MAO$\mathrm{B}$ levels akin to that observed in aging and neurodegenerative disease results in metabolic stress within the respiratory apparatus by affecting components contributing to NADH levels. Upon MAO-B induction, activity of all the enzymes examined diminishes and the maximal respiration which can be supported was found to be decreased. The spare capacity and the respiratory threshold of each enzyme were found to be reduced to varying degrees, near zero in the case of both Complex I and KDGH under the high energy demand conditions examined.

Under non-stress conditions, the sum of the control coefficients of all components examined is 0.6153 , indicating that there are likely other contributors to metabolic control in the uninduced cells. In the stress condition, the sum of control coefficients of all components examined increases to 0.9473 , indicating that the enzymes studied have a large control over respiration in this situation. Mitochondrial CI has been reported to be particularly sensitive to oxidative stress and its inhibition hypothesized to play a major role in mitochondrial dysfunction associated with PD (Schapira et al. 1989; Mizuno et al. 1990; Lenaz et al. 1997). We found that it plays a major role in our system under both control and MAO-B induced conditions. The spare capacity and threshold of inhibition of KDGH also appears to be reduced to zero under the stress conditions examined in this study. $\mathrm{KGDH}$ too has been reported to be sensitive to damage by $\mathrm{H}_{2} \mathrm{O}_{2}$ and itself is a source of $\mathrm{H}_{2} \mathrm{O}_{2}$ when substrate-limited (Tretter and Adam-Vizi 2004; Starkov et al. 2004). Other mitochondrial enzymes are also affected in our model but with less effect on their spare capacities or inhibition thresholds. PDH has been reported to be impacted by $\mathrm{H}_{2} \mathrm{O}_{2}$ generated during ischemia (Bogaert et al. 1994; Samikkannu et al. 2003; Tabatabaie et al. 1996). Similarly, SDH has also been reported to be sensitive to $\mathrm{H}_{2} \mathrm{O}_{2}$ (Nulton-Persson and Szweda 2001; Tretter and AdamVizi 2000). Our data indicates that although all the enzymes examined are inhibited under MAO-B induced stress, there is a vast difference in the control they exert on mitochondrial respiration. CI inhibition by MAO-B induced stress appears to be more important than inhibition of the other enzymes examined in this study suggesting that intervention to prevent dopaminergic mitochondrial dysfunction should be directed toward preservation of $\mathrm{CI}$ activity although $\mathrm{KGDH}$ may also be of some import especially when its effects are separated from PDH activity.
Acknowledgments We thank Dr. Martin Brand, Cambridge, UK for his useful comments regarding this work. This work was funded by NIH grant NS04165 (JKA).

Open Access This article is distributed under the terms of the Creative Commons Attribution Noncommercial License which permits any noncommercial use, distribution, and reproduction in any medium, provided the original author(s) and source are credited.

\section{References}

Bogaert YE, Rosenthal RE, Fiskum G (1994) Postischemic inhibition of cerebral cortex pyruvate dehydrogenase. Free Radic Biol Med 16:811-820

Brand MD, Vallis BP, Kesseler A (1994) The sum of flux control coefficients in the electron-transport chain of mitochondria. Eur J Biochem 226:819-829

Cascante M, Boros LG, Comin-Anduix B et al (2002) Metabolic control analysis in drug discovery and disease. Nat Biotechnol 20:243-249

Cohen G, Kesler N (1999) Monoamine oxidase and mitochondrial respiration. J Neurochem 73:2310-2315

Cohen G, Farooqui R, Kesler N (1997) Parkinson disease: a new link between monoamine oxidase and mitochondrial electron flow. Proc Natl Acad Sci USA 94:4890-4894

Cornish-Bowden A (2004) Fundamentals of enzyme kinetics, 3rd edn. Portland Press, London

Davey GP, Clark JB (1996) Threshold effects and control of oxidative phosphorylation in nonsynaptic rat brain mitochondria. J Neurochem 66:1617-1624

Davey GP, Canevari L, Clark JB (1997) Threshold effects in synaptosomal and nonsynaptic mitochondria from hippocampal CA1 and paramedian neocortex brain regions. J Neurochem 69:2564-2570

Davey GP, Peuchen S, Clark JB (1998) Energy thresholds in brain mitochondria. Potential involvement in neurodegeneration. J Biol Chem 273:12753-12757

Harper ME, Monemdjou S, Ramsey JJ, Weindruch R (1998) Agerelated increase in mitochondrial proton leak and decrease in ATP turnover reactions in mouse hepatocytes. Am J Physiol 275:E197-E206

Kacser H, Burns JA (1973) The control of flux. Symp Soc Exp Biol 27:65-104

Kacser H, Burns JA (1979) MOlecular democracy: who shares the controls? Biochem Soc Trans 7:1149-1160

Kumar MJ, Nicholls DG, Andersen JK (2003) Oxidative alphaketoglutarate dehydrogenase inhibition via subtle elevations in monoamine oxidase B levels results in loss of spare respiratory capacity: implications for Parkinson's disease. J Biol Chem 278:46432-46439

Kunz WS, Kuznetsov AV, Clark JF, Tracey I, Elger CE (1999) Metabolic consequences of the cytochrome c oxidase deficiency in brain of copper-deficient Mo(vbr) mice. J Neurochem 72:15801585

Lenaz G, Bovina C, Castelluccio C et al (1997) Mitochondrial complex I defects in aging. Mol Cell Biochem 174:329-333

Letellier T, Heinrich R, Malgat M, Mazat JP (1994) The kinetic basis of threshold effects observed in mitochondrial diseases: a systemic approach. Biochem J 302(Pt 1):171-174

Mazat JP, Rossignol R, Malgat M et al (2001) What do mitochondrial diseases teach us about normal mitochondrial functions that we already knew: threshold expression of mitochondrial defects. Biochim Biophys Acta 1504:20-30 
Mizuno Y, Suzuki K, Ohta S (1990) Postmortem changes in mitochondrial respiratory enzymes in brain and a preliminary observation in Parkinson's disease. J Neurol Sci 96:49-57

Mizuno Y, Matuda S, Yoshino H et al (1994) An immunohistochemical study on alpha-ketoglutarate dehydrogenase complex in Parkinson's disease. Ann Neurol 35:204-210

Murphy AN, Bredesen DE, Cortopassi G, Wang E, Fiskum G (1996) Bcl-2 potentiates the maximal calcium uptake capacity of neural cell mitochondria. Proc Natl Acad Sci USA 93:9893-9898

Nulton-Persson AC, Szweda LI (2001) Modulation of mitochondrial function by hydrogen peroxide. J Biol Chem 276:23357-23361

Rossignol R, Faustin B, Rocher C et al (2003) Mitochondrial threshold effects. Biochem J 370:751-762

Samikkannu T, Chen CH, Yih LH et al (2003) Reactive oxygen species are involved in arsenic trioxide inhibition of pyruvate dehydrogenase activity. Chem Res Toxicol 16:409-414

Schapira AH (1999) Mitochondrial involvement in Parkinson's disease, Huntington's disease, hereditary spastic paraplegia and Friedreich's ataxia. Biochim Biophys Acta 1410:159-170

Schapira AH, Cooper JM, Dexter D et al (1989) Mitochondrial complex I deficiency in Parkinson's disease. Lancet 1:1269

Schapira AH, Cooper JM, Dexter D et al (1990) Mitochondrial complex I deficiency in Parkinson's disease. J Neurochem 54:823-827

Starkov AA, Fiskum G, Chinopoulos C et al (2004) Mitochondrial alpha-ketoglutarate dehydrogenase complex generates reactive oxygen species. J Neurosci 24:7779-7788
Tabatabaie T, Potts JD, Floyd RA (1996) Reactive oxygen speciesmediated inactivation of pyruvate dehydrogenase. Arch Biochem Biophys 336:290-296

Tretter L, Adam-Vizi V (2000) Inhibition of Krebs cycle enzymes by hydrogen peroxide: a key role of [alpha]-ketoglutarate dehydrogenase in limiting NADH production under oxidative stress. J Neurosci 20:8972-8979

Tretter L, Adam-Vizi V (2004) Generation of reactive oxygen species in the reaction catalyzed by alpha-ketoglutarate dehydrogenase. $\mathbf{J}$ Neurosci 24:7771-7778

Trounce IA, Kim YL, Jun AS, Wallace DC (1996) Assessment of mitochondrial oxidative phosphorylation in patient muscle biopsies, lymphoblasts, and transmitochondrial cell lines. Methods Enzymol 264:484-509

Villani G, Attardi G (1997) In vivo control of respiration by cytochrome $\mathrm{c}$ oxidase in wild-type and mitochondrial DNA mutation-carrying human cells. Proc Natl Acad Sci USA 94:1166-1171

Villani G, Greco M, Papa S, Attardi G (1998) Low reserve of cytochrome c oxidase capacity in vivo in the respiratory chain of a variety of human cell types. J Biol Chem 273:31829-31836

Vindis C, Seguelas MH, Lanier S, Parini A, Cambon C (2001) Dopamine induces ERK activation in renal epithelial cells through $\mathrm{H} 2 \mathrm{O} 2$ produced by monoamine oxidase. Kidney Int 59:76-86 